(2) Open Access Full Text Article

ORIGINALRESEARCH

\title{
Lymph-Vascular Space Invasion in Patients with Stages IA2-IIA2 Cervical Cancer Treated with Laparoscopic versus Open Radical Hysterectomy
}

This article was published in the following Dove Press journal: Cancer Management and Research

\section{Wancheng Zhao \\ Qing Yang (D)}

Department of Obstetrics and Gynecology, Shengjing Hospital of China Medical University, Shenyang, People's Republic of China
Correspondence: Qing Yang Email Yangqing_sj@I26.com
Objective: To explore the relationship between laparoscopic radical hysterectomy (LRH) and cervical cancer lymph-vascular space invasion (LVSI) by comparing the prevalence of LVSI in cervical cancer patients who underwent LRH versus open radical hysterectomy (ORH).

Methods: The study participants were 1087 cervical cancer patients (FIGO 2009 stages IA2-IIA2) with pathologically confirmed with or without LVSI who underwent radical hysterectomy at Shengjing Hospital of China Medical University from 2013 through 2018. The patients were divided according to the type of surgical procedure into an LRH group $(\mathrm{n}=148)$ and an ORH group ( $\mathrm{n}=939)$.

Results: In the LRH group, $31.76 \%$ of patients (47/148) had LVSI-positive tumors compared to $33.23 \%$ of patients (312/939) in the ORH group; the difference was not significant $(\mathrm{p}=0.724)$. No between-group differences in LVSI prevalence according to lymph node metastasis, interstitial infiltration depth, differentiation degree, and parametrial infiltration were found. However, the number of LVSI-positive patients whose cervical cancer lesions $>4 \mathrm{~cm}$ (stage I B2 and II A2) was significantly higher in the LRH group than in the ORH group (Odds Ratio [OR] 0.333, 95\% confidence interval [CI] 0.157-0.706, p=0.005). The 3 -Year disease-free survival (DFS) in the LRH group is lower than that in the ORH group (94.75\% vs $97.27 \%)$, but there was no significance $(\mathrm{P}=0.187)$. Furthermore, the percentage of LVSI-positive tumors in patients with lymph node metastases was significantly higher than those without lymph node metastases (OR 2.897, 95\% CI 2.129-3.942, $\mathrm{p}=0.000$ ). The 3 -Year DFS were $98.22 \%$ in the LVSI negative patients and $93.78 \%$ in the LVSI positive patients, the difference was significant $(\mathrm{P}=0.002)$.

Conclusion: A higher risk of lymph node metastasis and a lower 3-Year DFS was found in the LVSI-positive patients. In case of LVSI, it would be dangerous to treat patient in laparoscopy, especially in case of cervical cancer lesions $>4 \mathrm{~cm}$.

Keywords: laparoscopic, cervical cancer, lymph-vascular space invasion, LVSI, radical hysterectomy

\section{Introduction}

Since Nezhat ${ }^{1}$ reported the first case of total laparoscopic radical hysterectomy (LRH) in 1992, many more studies ${ }^{2-7}$ have suggested that LRH is a feasible and safe surgical treatment option for cervical cancer, and it has advantages such as less bleeding, a lower risk of infection, more rapid postoperative recovery, and shorter hospital stay, with similar relapse, 5-year survival, and tumor-free survival rates, compared with open radical hysterectomy (ORH). Therefore, LRH for cervical 
cancer has been gradually accepted and popularized by both doctors and patients. The 2018 National Comprehensive Cancer Network (NCCN) Guidelines recommend treating stages IA2-IIA cervical cancer with ORH, LRH, or robot-assisted LRH.

However, a prospective, multi-center, randomized controlled study, reported in 2018 by Ramirez et al, ${ }^{8}$ showed that the LVSI-positive patients with stage IA1, IA2, and IB1 cervical cancer had poorer prognoses after LRH than after ORH. Meanwhile, Melamed et $\mathrm{al}^{9}$ drew a similar conclusion from a retrospective epidemiologic study. Compared with other positive studies, ${ }^{10-15}$ these reports of negative effects of LRH took the international gynecological research and practice community by surprise. LVSI is one of the factors used to select the subsequent treatment plan in cervical cancer patients and influences their prognosis. The aim of this study was to explore the effects of LRH on LVSI by comparing the prevalence of LVSI in cervical cancer patients who underwent LRH or ORH.

\section{Methods}

\section{Patients}

The study participants were 1087 cervical cancer patients treated at Shengjing Hospital of China Medical University from 2013 through 2018. The inclusion criteria were as follows: 1) a clinical diagnosis of FIGO 2009 stage IA2IIA2 cervical cancer, 2) initial treatment by LRH or ORH, 3) a pathologic diagnosis of squamous cell carcinoma with or without LVSI, but no LVSI-positive patients on pre-operative cervical biopsies. 4) absence of malignant or borderline tumors at other sites. 5) no neo adjuvant chemotherapy prior to surgery. 6) All patients underwent systematic pelvic lymph node dissection, with or without aortic lymph node dissection. 7) Sentinel lymph nodes were not performed. Postoperative adjuvant therapy was performed according to Sedlis standard for those patients with moderate risk factors, or to those with three high-risk factors (lymph node metastasis, parametrial infiltration and positive surgical margin). Based on the initial operation mode, the patients were divided into an LRH group and an ORH group. In the patients who underwent $\mathrm{LRH}, \mathrm{CO}_{2}$-insufflated pneumoperitoneum was established, and a cup-type uterine manipulator was used during the operation. The LRH group patients had a mean age $47.02 \pm 8.70$ years (range, 25-68 years) and the ORH group patients had a mean age of 49.53 \pm 9.32 years (range, 22 to 77 years). There was no significant difference in the age and clinical stage distribution between the two groups $(p=0.211$ and 0.917 , respectively) (Table 1).

\section{Follow-Up}

Patients who underwent surgery between January 1, 2013 and December 31, 2016 were followed up by professional gynecologists through telephone. And the last follow-up time was December 31, 2019. The postoperative adjuvant chemoradiotherapy conditions, survival status, survival time, reasons of death, recurrence time and location were recorded. Disease-free survival (DFS) and overall survival (OS) were calculated. DFS was defined as the time (months) from surgery to recurrence. OS was defined as the time (months) from surgery to death. Data of patients with no evidence of death or recurrence was censored.

\section{Methods}

Normally distributed quantitative data are presented as mean \pm standard deviation (SD). Independent Samples were analyzed using Mann-Whitney $U$-Test. The qualitative data were analyzed with the $\chi 2$ test or Fisher's Exact Test. Survival analysis was carried out through Kaplan-

Table I The Characteristics of the Patients Who Underwent Laparoscopic versus Open Radical Hysterectomy

\begin{tabular}{|c|c|c|c|c|c|}
\hline & \multicolumn{2}{|c|}{ LRH } & \multicolumn{2}{|c|}{ ORH } & \multirow[t]{2}{*}{$P$ value } \\
\hline & $\mathbf{n}$ & $\%$ & $\mathbf{n}$ & $\%$ & \\
\hline Age (years) & \multicolumn{2}{|c|}{$47.02 \pm 8.70$} & \multicolumn{2}{|c|}{$49.53 \pm 9.32$} & 0.211 \\
\hline IA2 & 4 & 2.70 & 10 & 1.06 & \\
\hline$|B|$ & 72 & 48.65 & 396 & 42.17 & \\
\hline IB2 & 9 & 6.08 & 136 & 14.48 & \\
\hline||$A \mid$ & 41 & 27.70 & 216 & 23.00 & \\
\hline IIA2 & 22 & 14.86 & 181 & 19.28 & \\
\hline Total & 148 & & 939 & & \\
\hline
\end{tabular}

Abbreviations: LRH, laparoscopic radical hysterectomy; ORH, open radical hysterectomy. 
Meier method and compared with Log rank test. Univariate and multivariate Cox proportional hazards regression analysis were used to calculate the factors associated with the DFS and OS of the cervical cancer patients. The data analysis was conducted through Statistical Package for Social Sciences (IBM SPSS, Version 25, Armonk, NY) and R version 4.0.3 (R Foundation for Statistical Computing, Vienna, Austria). A p-value $<0.05$ indicated a statistically significant difference.

\section{Results}

\section{Clinical Staging and LVSI}

Of the 1087 patients, 148 (13.62\%) composed the LRH group and $939(86.38 \%)$ composed the ORH group. Fortyseven patients $(31.76 \%)$ in the LRH group and 312 patients $(33.23 \%)$ in the ORH group had positive LVSI; the difference was not significant $(\mathrm{p}=0.724)$. A total of 468 patients (LRH, 72, 48.65\% and ORH, 396, 42.17\%) were classified as clinical stage IB1, accounting for $43.05 \%$ of the study participants; $20(27.78 \%)$ and $144(36.36 \%)$ patients with LVSI-positive tumors in the LRH and ORH groups, respectively, were classified as stage IB1. The overall betweengroup difference was not significant $(\mathrm{p}=0.18)$. No significant between-group difference in LVSI prevalence was observed in patients diagnosed with stage IA2 combining IB1 and stage IIA cervical cancers ( $p=0.240$ and 0.468 , respectively). The clinical stage distribution and LVSI status of the patients in the two groups are shown in Table 2.

\section{Lesion Size and LVSI}

There were significantly more patients with LVSI-positive cervical cancer lesions $>4 \mathrm{~cm}$ (stage I B2 and II A2) in the LRH group than in the ORH group (Odds Ratio [OR] 0.333, $95 \%$ confidence interval $[\mathrm{CI}] 0.157-0.706, \mathrm{p}=0.005)$, but there was no significant between-group difference in the number of patients with LVSI-positive cervical cancer lesions $\leq 4 \mathrm{~cm}$ (stage IA2, IB1, and IIA1) ( $\mathrm{p}=0.053$ ). No significant betweengroup differences were found in the number of patients with LVSI-positive cervical cancer lesions $\leq 2 \mathrm{~cm}$ and $>2 \mathrm{~cm}$ $(p=0.271$ and 0.605 , respectively) or $\leq 2 \mathrm{~cm}$ and $2-4 \mathrm{~cm}$ (stage IB1) ( $\mathrm{p}=0.690$ and 0.207 , respectively). (Table 3)

\section{Lymph Node Metastasis and LVSI}

Twenty-three patients (15.54\%) in the LRH group and 188 patients $(20.02 \%)$ in the ORH group had lymph node metastasis; the difference was not significant $(p=0.220)$. No between-group difference was found in the number of LVSIpositive patients regardless of lymph node metastasis ( $\mathrm{p}=0.826$ and 0.831 , respectively). Forty-three patients $(29.05 \%)$ in the LRH group and 318 patients $(33.87 \%)$ in the ORH group underwent aortic lymph node dissection, and all aortic lymph node metastases were associated with pelvic lymph node metastases. Furthermore, the number of LVSIpositive patients with lymph node metastasis was markedly higher than the number of LVSI-positive patients without lymph node metastasis in both groups (OR 3.479, 95\% CI 1.395-8.676, $\mathrm{p}=0.008$ and OR 2.810, 95\% CI 2.025-3.898, $\mathrm{p}=0.000$, respectively). Finally, the percentage of LVSIpositive patients among the patients with lymph node metastasis and aortic lymph node metastases was also significantly higher than among the patients without lymph node metastasis and aortic lymph node metastases (OR 2.881, 95\% CI 2.118-3.919, $\mathrm{p}=0.000$ and OR 5.625, 95\% CI 1.905-16.611, $\mathrm{p}=0.001)($ Table 4$)$.

\section{Interstitial Infiltration Depth, Differentiation Degree, or Periuterine Invasion and Prevalence of LVSI}

Among the patients with tumors showing interstitial infiltration depth $>1 / 2 \mathrm{~cm}$ and $\leq 1 / 2 \mathrm{~cm}$, there were 29 and 18

Table 2 Lymph-Vascular Space Invasion (LVSI) According to Clinical Stage in Patients Who Underwent Laparoscopic or Open Radical Hysterectomy

\begin{tabular}{|c|c|c|c|c|c|c|c|c|}
\hline \multirow[t]{2}{*}{ LRH/ORH } & \multirow[t]{2}{*}{ FIGO Stage } & \multicolumn{2}{|l|}{ LVSI (-) } & \multicolumn{2}{|c|}{ LVSI (+) } & \multicolumn{2}{|l|}{ Total } & \multirow[t]{2}{*}{$\mathbf{P}$ value } \\
\hline & & & $\%$ & & $\%$ & & $\%$ & \\
\hline & IA2 & $2 / 6$ & $1.35 / 0.64$ & $2 / 4$ & $1.35 / 0.43$ & $4 / 10$ & $2.70 / 1.06$ & 0.18 \\
\hline & $|B|$ & $52 / 252$ & $35.14 / 26.84$ & $20 / 144$ & $13.5|/| 5.34$ & $72 / 396$ & $48.65 / 42.17$ & \\
\hline & IB2 & $6 / 93$ & $4.05 / 9.90$ & $3 / 43$ & $2.03 / 4.58$ & $9 / 136$ & $6.08 / 14.48$ & \\
\hline & $\| A \mid$ & $34 / 152$ & $22.97 / 16.19$ & $7 / 64$ & $4.73 / 6.82$ & $4 I / 216$ & $27.70 / 23.00$ & \\
\hline & IIA2 & $7 / 124$ & $4.73 /|3.2|$ & $15 / 57$ & $10.14 / 6.07$ & $22 / 181$ & $14.86 / 19.28$ & \\
\hline & Total & $101 / 627$ & $68.24 / 66.77$ & $47 / 312$ & $31.76 / 33.23$ & $148 / 939$ & $100 / 100$ & \\
\hline
\end{tabular}

Abbreviations: LRH, laparoscopic radical hysterectomy; ORH, open radical hysterectomy. 
Table 3 Lymph-Vascular Space Invasion According to Size of Cervical Cancer Lesion in Patients Who Underwent Laparoscopic versus Open Radical Hysterectomy

\begin{tabular}{|c|c|c|c|c|c|c|c|}
\hline & & \multicolumn{2}{|c|}{ LVSI (-) } & \multicolumn{2}{|c|}{ LVSI (+) } & \multirow[t]{2}{*}{ Total } & \multirow[t]{2}{*}{$P$ value } \\
\hline & & & $\%$ & & $\%$ & & \\
\hline \multirow[t]{2}{*}{ LRH/ORH } & Cervical cancer lesions $\leq 4 \mathrm{~cm}$ & $88 / 410$ & $75.21 / 65.92$ & $29 / 212$ & $24.79 / 34.08$ & $117 / 622$ & 0.053 \\
\hline & Cervical cancer lesions $>4 \mathrm{~cm}$ & $13 / 217$ & $41.94 / 68.45$ & $18 / 100$ & $58.06 / 31.55$ & $31 / 317$ & 0.005 \\
\hline \multirow[t]{2}{*}{ LRH/ORH } & Cervical cancer lesions $\leq 2 \mathrm{~cm}$ & $51 / 212$ & $71.83 / 64.24$ & $20 / 118$ & $28.17 / 35.76$ & $71 / 330$ & 0.271 \\
\hline & Cervical cancer lesions $>2 \mathrm{~cm}$ & $50 / 415$ & $64.94 / 68.14$ & $27 / 194$ & $35.06 / 31.86$ & $77 / 609$ & 0.605 \\
\hline \multirow[t]{2}{*}{ LRH/ORH (stage IBI) } & Cervical cancer lesions $\leq 2 \mathrm{~cm}$ & $24 / 101$ & $70.59 / 65.16$ & $10 / 54$ & $29.41 / 34.84$ & $34 / 155$ & 0.690 \\
\hline & Cervical cancer lesions $2 \sim 4 \mathrm{~cm}$ & $28 / 151$ & $73.68 / 62.66$ & $10 / 90$ & $26.32 / 37.34$ & $38 / 241$ & 0.207 \\
\hline
\end{tabular}

Abbreviations: LRH, laparoscopic radical hysterectomy; ORH, open radical hysterectomy.

Table 4 Lymph-Vascular Space Invasion in Cervical Carcinoma Patients with Lymph Node Metastases Who Underwent Laparoscopic versus Open Radical Hysterectomy

\begin{tabular}{|c|c|c|c|c|c|c|c|}
\hline & & \multicolumn{2}{|c|}{ LVSI (-) } & \multicolumn{2}{|c|}{ LVSI (+) } & \multirow[t]{2}{*}{ Total } & \multirow[t]{2}{*}{$P$ value } \\
\hline & & & $\%$ & & $\%$ & & \\
\hline LRH/ORH & $\begin{array}{l}\text { Lymph node metastatic carcinoma } \\
\text { No }\end{array}$ & $\begin{array}{l}10 / 89 \\
91 / 538\end{array}$ & $\begin{array}{l}43.48 / 47.34 \\
72.80 / 71.64\end{array}$ & $\begin{array}{l}13 / 99 \\
34 / 213\end{array}$ & $\begin{array}{l}56.52 / 52.66 \\
27.20 / 28.36\end{array}$ & $\begin{array}{l}23 / \mid 88 \\
|25 / 75|\end{array}$ & $\begin{array}{l}0.826 \\
0.831\end{array}$ \\
\hline LRH/ORH & $\begin{array}{l}\text { Aortic lymph node metastasis } \\
\text { No }\end{array}$ & $\begin{array}{l}0 / 5 \\
28 / 220\end{array}$ & $\begin{array}{l}0 / 33.33 \\
66.67 / 72.61\end{array}$ & $\begin{array}{l}1 / 10 \\
14 / 83\end{array}$ & $\begin{array}{l}100 / 66.67 \\
33.33 / 27.39\end{array}$ & $\begin{array}{l}1 / 15 \\
42 / 303\end{array}$ & $\begin{array}{l}1.000 \\
0.465\end{array}$ \\
\hline
\end{tabular}

Abbreviations: LRH, laparoscopic radical hysterectomy; ORH, open radical hysterectomy.

cases of positive LVSI in the LRH group, and 224 and 88 cases of positive LVSI in the ORH group, respectively; no significant between-group differences were observed $(\mathrm{p}=0.812$ and 1.000$)$. Among the patients with tumors showing high, moderate, and low differentiation, there were no statistical between-group differences in LVSI $(\mathrm{p}=0.208,0.459$, and 1.000). None of patient's tumors were positive for parametrial infiltration (Table 5).

\section{Survival Analysis}

Median follow-up was 47 months (range, 36-74months) in the ORH group versus 63 months (range, 36-
75 months) in the LRH group. Among all the 715 patients who were followed up, 5 patients had recurrence in the LRH group and 17 patients had recurrence in the ORH group, 1 patients died in the LRH and 5 patients died in the ORH group (Table 6). The 3-Year OS were $98.91 \%$ in the LRH group and $99.20 \%$ in the ORH group (LogRank $\mathrm{P}=0.564$, Figure 1C). Accordingly, the 3-Year mortality were $1.09 \%$ and $0.8 \%$ (Log-Rank $\mathrm{P}=0.564)$. The 3-Year DFS were $94.75 \%$ and $97.27 \%$ for the LRH and ORH groups, respectively. The 3-Year DFS in the LRH group is lower, but there was no significance (Log-Rank $\mathrm{P}=0.187$, Figure 1D). Besides, there were 3 deaths in the

Table 5 Lymph-Vascular Space Invasion According to Interstitial Infiltration Depth and Differentiation in Patients Who Underwent Laparoscopic versus Open Radical Hysterectomy

\begin{tabular}{|l|l|l|l|l|l|l|l|}
\hline \multirow{2}{*}{} & \multicolumn{2}{|l|}{ LVSI (-) } & \multicolumn{2}{l|}{ LVSI (+) } & Total & P value \\
\cline { 3 - 8 } & & & $\%$ & & $\%$ & \\
\hline \multirow{2}{*}{ LRH/ORH } & Interstitial infiltration depth $\leq 1 / 2 \mathrm{~cm}$ & $42 / 203$ & $70.00 / 69.76$ & $18 / 88$ & $30.00 / 30.24$ & $60 / 291$ & 0.812 \\
& Interstitial infiltration depth $>1 / 2 \mathrm{~cm}$ & $59 / 424$ & $67.05 / 65.43$ & $29 / 224$ & $32.95 / 34.57$ & $88 / 648$ & 1.000 \\
\hline \multirow{2}{*}{ LRH/ORH } & High differentiation & $5 / 40$ & $55.56 / 78.43$ & $4 / 11$ & $44.44 / 21.57$ & $9 / 51$ & 0.208 \\
& Moderate differentiation & $81 / 533$ & $70.43 / 66.79$ & $34 / 265$ & $29.57 / 33.21$ & $1 / 5 / 798$ & 0.459 \\
& Low differentiation & $15 / 54$ & $62.50 / 60.00$ & $9 / 36$ & $37.5 / 40.00$ & $24 / 90$ & 1.000 \\
\hline
\end{tabular}

Abbreviations: LRH, laparoscopic radical hysterectomy; ORH, open radical hysterectomy. 
Table 6 The Follow-Up Cases of the Two Groups from 2013 to 2016

\begin{tabular}{|c|c|c|c|c|c|c|c|c|c|c|}
\hline \multirow[t]{2}{*}{ LRH/ORH } & \multirow[t]{2}{*}{ FIGO Stage } & \multicolumn{2}{|c|}{ LVSI (-) } & \multicolumn{2}{|c|}{ LVSI (+) } & \multirow[t]{2}{*}{ Total } & \multicolumn{2}{|l|}{ LVSI (-) } & \multicolumn{2}{|l|}{ LVSI (+) } \\
\hline & & & $\%$ & & $\%$ & & Recurrence & Death & Recurrence & Death \\
\hline & IA2 & $2 / 4$ & $2.17 / 0.64$ & $1 / 3$ & $1.09 / 0.48$ & $3 / 7$ & $0 / 0$ & $0 / 0$ & $0 / 0$ & $0 / 0$ \\
\hline & $|B|$ & $32 / 167$ & $34.78 / 26.81$ & $|3 / 8|$ & $14.13 / 13.00$ & $45 / 248$ & $0 / 2$ & $0 / 0$ & $1 / 2$ & $0 / 1$ \\
\hline & IB2 & $3 / 69$ & $3.26 / 11.08$ & $2 / 15$ & $2.17 / 2.41$ & $5 / 84$ & $0 / 1$ & $0 / 0$ & $1 / 3$ & $0 / 0$ \\
\hline & $\| \mathrm{AI}$ & $18 / 113$ & $19.57 / 18.14$ & $4 / 44$ & $4.35 / 7.06$ & $22 / 157$ & $\mathrm{I} / \mathrm{I}$ & $1 / 1$ & $1 / 4$ & $0 / 2$ \\
\hline & IIA2 & $4 / 94$ & $4.35 / 15.09$ & $13 / 33$ & $14.13 / 5.30$ & $17 / 127$ & $1 / 3$ & $0 / 1$ & $0 / 1$ & $0 / 0$ \\
\hline & Total & $59 / 447$ & $64.13 / 71.75$ & $33 / 176$ & $35.87 / 28.25$ & $92 / 623$ & $2 / 7$ & $1 / 2$ & $3 / 10$ & $0 / 3$ \\
\hline
\end{tabular}

Abbreviations: LRH, laparoscopic radical hysterectomy; ORH, open radical hysterectomy.

LVSI negative patients and 3 deaths in the LVSI positive patients. The 3-Year OS were $99.41 \%$ and $98.56 \%$, respectively (Log-Rank $\mathrm{P}=0.259$, Figure 1A). The 3 -Year DFS were $98.22 \%$ in the LVSI negative patients and $93.78 \%$ in the LVSI positive patients, the difference was significant (Log-Rank $\mathrm{P}=0.002$, Figure 1B).

A

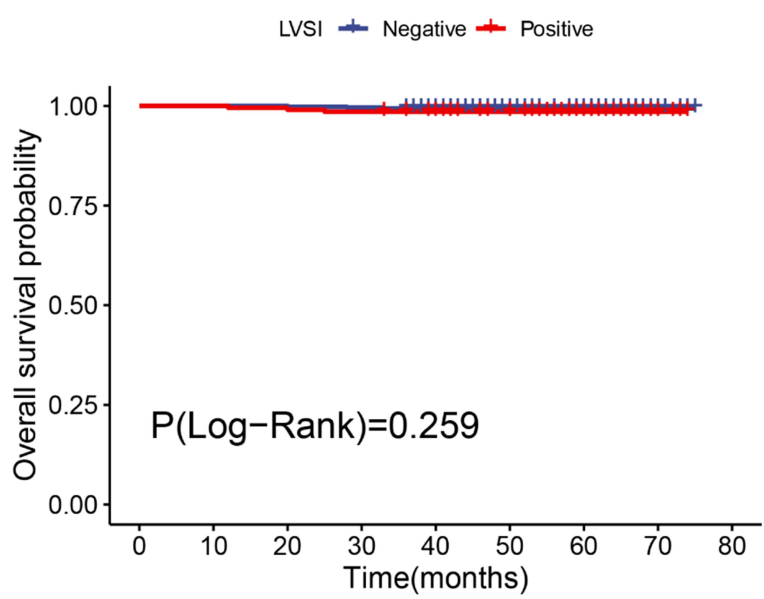

C

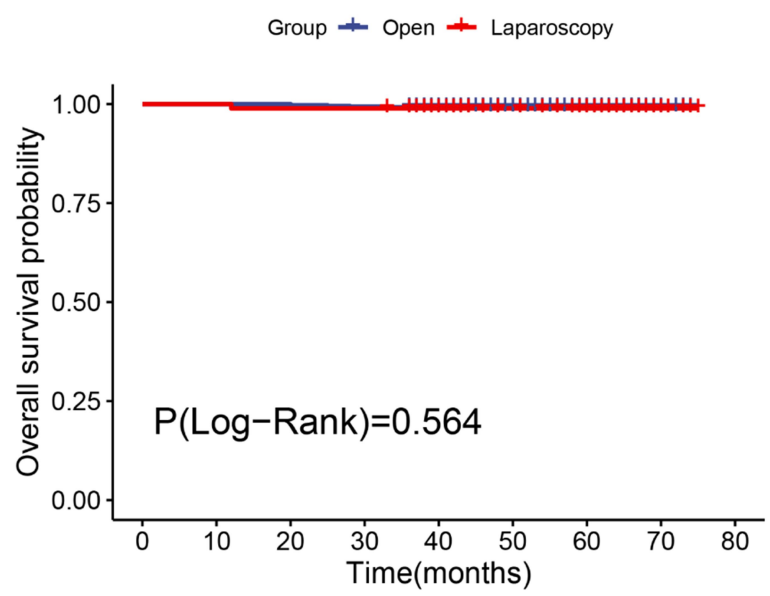

Furthermore, univariate and multivariate Cox analysis were conducted to identify the factors associated with the DFS of the cervical cancer patients. Through univariate Cox analysis, tumor size, LVSI, interstitial infiltration depth, and lymph node metastases were identified to be associated with the DFS of the patients. Then, tumor size

B

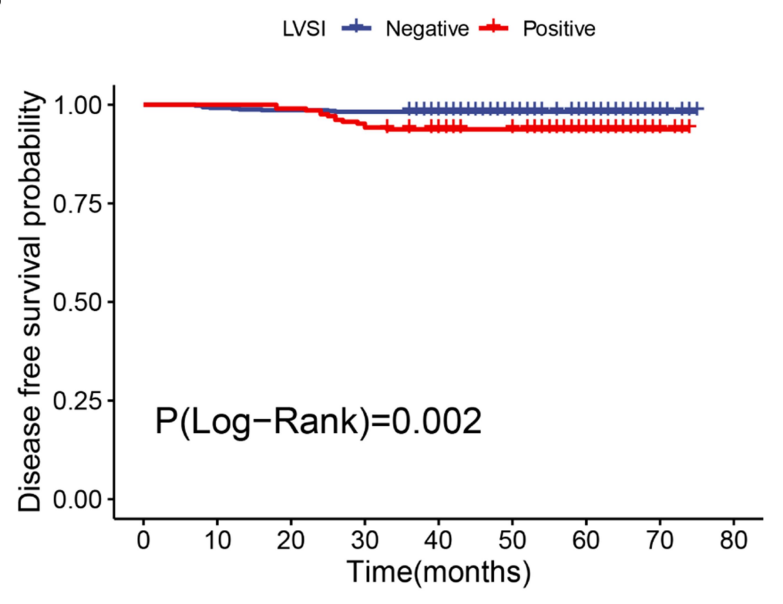

D

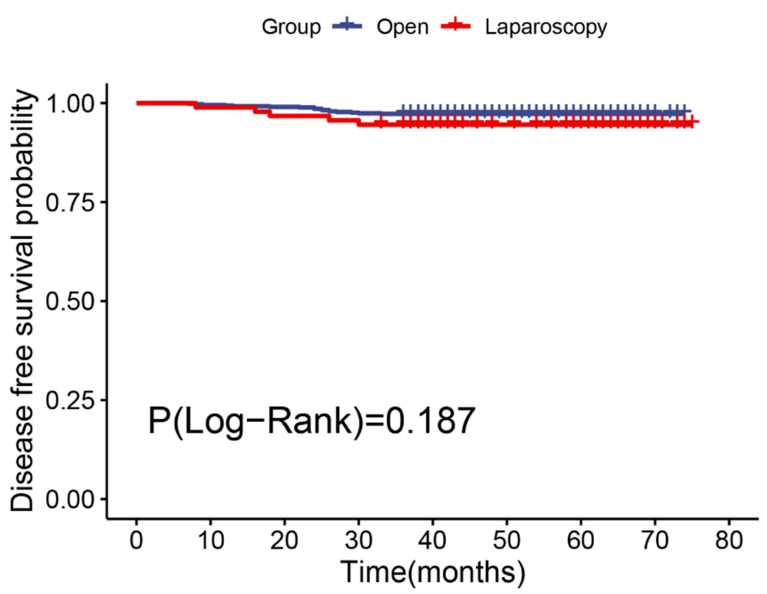

Figure I Survival outcomes of the followed up patients. (A) Overall survival (OS) curves of the lymph-vascular space invasion (LVSI) negative versus positive patients. (B) Disease-free survival (DFS) curves of the LVSI negative versus positive patients. (C) OS curves of the patients in the laparoscopic radical hysterectomy (LRH) group versus open radical hysterectomy (ORH) group. (D) DFS curves of the patients in the LRH group versus ORH group. 
$(\mathrm{HR}=2.369, \quad 95 \mathrm{CI} \%: \quad 1.215-3.211, \quad \mathrm{P}=0.008), \quad$ LVSI $(\mathrm{HR}=3.417,95 \mathrm{CI} \%: 1.457-8.011, \mathrm{P}=0.005)$ and interstitial infiltration depth $\quad(\mathrm{HR}=2.123, \quad 95 \mathrm{CI} \%: \quad 1.123-4.065$, $\mathrm{P}=0.021$ ) were proved to be independent prognostic factors of DFS for the cervical cancer patients through multivariate Cox analysis.

\section{Discussion}

Since the first report in $2018,{ }^{8,9}$ more studies ${ }^{16-18}$ have focused on the possible adverse effects of LRH on the prognosis of patients with early cervical cancer, and some have recommended ORH for cervical cancer patients. ${ }^{19}$ LVSI, tumor size, lymph node metastasis, interstitial infiltration depth, and parametrial infiltration all adversely influence the prognosis of early cervical cancer patients, ${ }^{20,21}$ and similar results were found in this study. In particular, we compared the prevalence of LVSI in cervical cancer patients who underwent LRH or ORH, and found that the number of patients with LVSI-positive cervical cancer lesions $>4 \mathrm{~cm}$ was significantly higher in the LRH group than in the ORH group $(\mathrm{p}=0.005)$. This finding suggests that in case of LVSI it would be dangerous to treat patient in laparoscopy, especially in case of bulky tumor.

$\mathrm{Hu}$ et $\mathrm{al}^{16}$ also found that at a tumor diameter $>4 \mathrm{~cm}$, the overall survival (OS) and progression-free survival (PFS) in a cohort of patients who underwent LRH were significantly shorter than in those who underwent abdominal radical hysterectomy (ARH), and they recommended ARH as the first-line surgical treatment option when the patient's tumor diameter is $>4 \mathrm{~cm}$. Pedone Anchora $\mathrm{L}$ et al observed in their study ${ }^{22}$ that at a tumor size $>20 \mathrm{~mm}$, LRH, compared with ORH, was significantly associated with an increased relapse rate, and they identified tumor size as the primary factor influencing surgical approach selection. In our study, however, no significant betweengroup differences in LVSI were found according to cervical cancer lesion size $\leq 2 \mathrm{~cm}$ and $>2 \mathrm{~cm}$, clinical stage, lymph node metastasis, and interstitial infiltration depth. The 3-year DFS of the patients in the LRH group is lower, but there was no significant between-group difference. Further, in our study, it would be more likely that LVSI is associated with a higher risk of lymph node metastases, regardless of LRH or ORH. There are studies ${ }^{23-27}$ indicating that LVSI, together with other pathological characteristics such as tumor size, result in an increased risk of lymph node metastasis, that is one of the most important prognostic factors in cervical cancer.
Unlike ORH, LRH requires the establishment of a pneumoperitoneum through $\mathrm{CO}_{2}$-insufflation and the application of a uterine manipulator and electric instruments. The continuously perfusing and flowing $\mathrm{CO}_{2}$ in pneumoperitoneum insufflation has a mechanical effect of diffusing the detached tumor cells and tissue particles, ${ }^{28-30}$ while the friction and compression effects of the uterine manipulator on the upper vagina and tumor tissues, and peritoneal contamination during intracorporal colpotomy may increase the risk of intraperitoneal tumor exposure, tumor cell detachment, local implantation and distant dissemination and metastasis $^{31-33}$. A larger cervical cancer tumor size corresponds to a higher risk of tumor exposure, compression, and detachment and a greater risk of tumor dissemination to the abdominopelvic cavity during laparoscopic surgery. ${ }^{34-38} \mathrm{In}$ our study, there were significantly more LVSI-positive patients with cervical cancer lesions $>4 \mathrm{~cm}$ in the LRH group than in the ORH group and LVSI is associated with a higher risk of lymph node metastases, which shows that cervical cancer lesion size $>4 \mathrm{~cm}$ greatly increases the risks of tumor exposure, dissemination and intralymphatic metastasis. We also found there was a lower 3-Year DFS in the patients with positive LVSI than those without positive LVSI. Considering the possible adverse effects of $\mathrm{CO}_{2}-$ insufflated pneumoperitoneum and the application of uterine manipulators and electric instruments, LRH may be a lesspreferred option for surgical treatment of patients with cervical cancer lesions $>4 \mathrm{~cm}$ or lymph node metastasis.

In conclusion, a higher risk of lymph node metastasis and a lower 3-Year DFS was found in the LVSI-positive patients. In case of LVSI, it would be dangerous to treat patient in laparoscopy, especially in case of cervical cancer lesions $>4 \mathrm{~cm}$. Thus, LRH may lead to possible adverse effects on the prognosis of these patients. ORH should be the first-line surgical treatment option for these patients. Review this article, we provide a new perspective to explore the adverse effects of LRH on cervical cancer, and we do have some new findings, but due to the limitation of small sample size and short follow-up time, further study is needed to identify the possible mechanisms of adverse effects of LRH on the prognosis of patients with cervical cancer.

\section{Ethics Statement}

This study was approved by the Shengjing Hospital of China Medical University Ethics Committee, and all patients were informed about the purpose of the study. The authors confirm that all participants provided 
informed consent to participate in this study, and that this study complied with the Declaration of Helsinki.

\section{Disclosure}

The authors declare that they have no conflicts of interest and have nothing to disclose.

\section{References}

1. Nezhat CR, Burrell MO, Nezhat FR, et al. Laparoscopic radical hysterectomy with paraaortic and pelvic node dissection. $\mathrm{Am}$ $J$ Obstet Gynecol. 1992;166(3):864-865. doi:10.1016/00029378(92)91351-A

2. Cao T, Feng Y, Huang Q, et al. Prognostic and safety roles in laparoscopic versus abdominal radical hysterectomy in cervical cancer: a meta-analysis. J Laparoendoscopic Adv Surg Tech. 2015;25 (12):990-998. doi:10.1089/lap.2015.0390

3. Sert BM, Boggess JF, Ahmad S, et al. Robot-assisted versus open radical hysterectomy: a multi-institutional experience for early-stage cervical cancer. Eur J Surg Oncol. 2016;42(4):513-522. doi:10.1016/ j.ejso.2015.12.014

4. Shah CA, Beck T, Liao JB, et al. Surgical and oncologic outcomes after robotic radical hysterectomy as compared to open radical hysterectomy in the treatment of early cervical cancer. J Gynecol Oncol. 2017;28(6):e82. doi:10.3802/jgo.2017.28.e82

5. Yang L, Cai J, Dong W, et al. Laparoscopic radical hysterectomy and pelvic lymphadenectomy can be routinely used for treatment of early-stage cervical cancer: a single-institute experience with 404 patients. J Minimally Invasive Gynecol. 2015;22(2):199-204. doi:10.1016/j.jmig.2014.09.009

6. Shazly SAM, Murad MH, Dowdy SC, et al. Robotic radical hysterectomy in early stage cervical cancer: a systematic review and meta-analysis Gynecol Oncol. 2015;138(2):457-471. doi:10.1016/j.ygyno.2015.06.009

7. Wang W, Chu HJ, Shang CL, et al. Long-term oncological outcomes after laparoscopic versus abdominal radical hysterectomy in stage IA2 to IIA2 cervical cancer: a matched cohort study. Int J Gynecol Cancer. 2016;26 (7):1264-1273. doi:10.1097/IGC.0000000000000749

8. Ramirez PT, Frumovitz M, Pareja R, et al. Minimally invasive versus abdominal radical hysterectomy for cervical cancer. $N$ Engl $J$ Med. 2018;379(20):1895-1904. doi:10.1056/NEJMoa1806395

9. Melamed A, Margul DJ, Chen L, et al. Survival after minimally invasive radical hysterectomy for early-stage cervical cancer. $N$ Engl $J$ Med. 2018;379(20):1905-1914. doi:10.1056/NEJMoa1804923

10. Gallotta V, Conte C, Federico A, et al. Robotic versus laparoscopic radical hysterectomy in early cervical cancer: a case matched control. Study Eur J Surg Oncol. 2018;44(6):754-759. doi:10.1016/j. ejso.2018.01.092

11. Corrado G, Vizza E, Legge F, et al. Comparison of different surgical approaches for stage IB1 cervical cancer patients: a multi-institution study and a review of the Literature.Int. J Gynecol Cancer. 2018;28 (5):1020-1028. doi:10.1097/IGC.0000000000001254

12. Nam J-H, Park J-Y, Kim D-Y, et al. Laparoscopic versus open radical hysterectomy in early-stage cervical cancer: long-term survival outcomes in a matched cohort study. Ann Oncol. 2012;23(4):903-911. doi:10.1093/annonc/mdr360

13. Park J-Y, Kim D-Y, Kim J-H, et al. Laparoscopic compared with open radical hysterectomy in obese women with early-stage cervical cancer. Obstet Gynecol. 2012;119(6):1201-1209. doi:10.1097/ AOG.0b013e318256ccc5

14. Diver E, Hinchcliff E, Gockley A, et al. Minimally invasive radical hysterectomy for cervical cancer is associated with reduced morbidity and similar survival outcomes compared with laparotomy. $J$ Minim Invasive Gynecol. 2017;24(3):402-406. doi:10.1016/j.jmig.2016.12.005
15. Park DA, Yun JE, Kim SW, Lee SH. Surgical and clinical safety and effectiveness of robot-assisted laparoscopic hysterectomy compared to conventional laparoscopy and laparotomy for cervical cancer: a systematic review and meta-analysis. Eur J Surg Oncol. 2017;43 (6):994-1002. doi:10.1016/j.ejso.2016.07.017

16. Hu TWY, Ming X, Yan HZ, Li ZY. Adverse effect of laparoscopic radical hysterectomy depends on tumor size in patients with cervical cancer. Cancer Manag Res. 2019;11:8249-8255. doi:10.2147/ CMAR.S216929

17. Kim SI, Lee M, Lee S, et al. Impact of laparoscopic radical hysterectomy on survival outcome in patients with FIGO stage IB cervical cancer: a matching study of two institutional hospitals in Korea. Gynecol Oncol. 2019;155(1):75-82. doi:10.1016/j.ygyno.201 9.07.019

18. Cusimano MC, Baxter NN, Gien LT, et al. Impact of surgical approach on oncologic outcomes in women undergoing radical hysterectomy for cervical cancer. Am J Obstet Gynecol. 2019;221 (6):619.e1-619. doi:10.1016/j.ajog.2019.07.009

19. Odetto D, Puga MC, Saadi J, Noll F, Perrotta M. Minimally invasive radical hysterectomy: an analysis of oncologic outcomes from Hospital Italiano (Argentina).. Int J Gynecol Cancer. 2019;29 (5):863-868. doi:10.1136/ijgc-2019-000323

20. Derks M, van der Velden J, de Kroon CD, et al. Surgical treatment of early-stage cervical cancer: a multi-institution experience in 2124 cases in the Netherlands over a 30-year period. Medicine. 2018;28 (4):757.

21. Boyraz G, Basaran D, Salman MC, et al. Clinical and pathological characteristics related to parametrial involvement in clinical early-stage cervical cancer. Ginekologia Polska. 2016;87 (6):417-421. doi:10.5603/GP.2016.0018

22. Pedone Anchora L, Turco LC, Bizzarri N, et al. How to select early-stage cervical cancer patients still suitable for laparoscopic radical hysterectomy: a propensity-matched study. Ann Surg Oncol. 2020;27(6):1947-1955. doi:10.1245/s10434-019-08162-5

23. Yan W, Qiu S, Ding Y, et al. Prognostic value of lymphovascular space invasion in patients with early stage cervical cancer in Jilin, China: a retrospective study. Medicine. 2019;98(40):e17301. doi:10.1097/MD.0000000000017301

24. Skręt-Magierło J, Soja PJ, Skręt A, et al. Perineural space invasion in cervical cancer (FIGO IB1-IIB) accompanied by high-risk factors for recurrence. J Cancer Res Ther. 2014;10(4):957-961. doi:10.4103/ 0973-1482.138126

25. Matsuo K, Shimada M, Saito T, et al. Risk stratification models for para-aortic lymph node metastasis and recurrence in stage IB-IIB cervical cancer. J Gynecol Oncol. 2018;29(1):e11. doi:10.3802/ jgo.2018.29.e11

26. Gulseren V, Kocaer M, Gungorduk O, et al. Preoperative predictors of pelvic and para-aortic lymph node metastases in cervical cancer. $J$ Cancer Res Ther. 2019;15(6):1231-1234. doi:10.4103/jert. JCRT_467_17

27. Fagotti A, Anchora LP, Conte C, et al. Beyond sentinel node algorithm. Toward a more tailored surgery for cervical cancer patients. Cancer Med. 2016;5(8):1725-1730. doi:10.1002/cam4.722

28. Volz J, Köster S, Spacek Z, et al. The influence of pneumoperitoneum used in laparoscopic surgery on an intraabdominal tumor growth. Cancer. 1999;86(5):770-774. doi:10.1002/(SICI)1097-0142(19990901)86:5<770::AID-CNCR11>3.0.CO;2-3

29. Mo L, et al. Effects of a simulated $\mathrm{CO} 2$ pneumoperitoneum environment on the proliferation, apoptosis, and metastasis of cervical cancer cells in vitro. Med Sci Monit. 2014;20:2497-2503. doi:10.12659/ MSM.891179

30. Kong T-W, Chang S-J, Piao X, et al. Patterns of recurrence and survival after abdominal versus laparoscopic/robotic radical hysterectomy in patients with early cervical cancer. J Obstet Gynaecol Res. 2016;42(1):77-86. doi:10.1111/jog. 12840 
31. Lim S, Kim HS, Lee KB, et al. Does the use of a uterine manipulator with an intrauterine balloon in total laparoscopic hysterectomy facilitate tumor cell spillage into the peritoneal cavity in patients with endometrial cancer? Int J Gynecol Cancer. 2008;18(5):1145-1149. doi:10.1111/j.1525-1438.2007.01165.x

32. Krizova A, Clarke BA, Bernardini MQ, et al. Histologic artifacts in abdominal, vaginal, laparoscopic, and robotic hysterectomy specimens: a blinded, retrospective review. Am J Surg Pathol. 2011;35 (1):115-126. doi:10.1097/PAS.0b013e31820273dc

33. Rakowski JA, Tran TAN, Ahmad S, et al. Does a uterine manipulator affect cervical cancer pathology or identification of lymphovascular space involvement? Gynecol Oncol. 2012;127(1):98-101. doi:10.1016/j.ygyno.2012.07.094

34. Casarin J, Buda A, Bogani G, et al. Predictors of recurrence following laparoscopic radical hysterectomy for early-stage cervical cancer: a multi-institutional study. Gynecol Oncol. 2020;159(1):164-170. doi:10.1016/j.ygyno.2020.06.508
35. Klapdor R, Hertel H, Hillemanns P, et al. Peritoneal contamination with ICG-stained cervical secretion as surrogate for potential cervical cancer tumor cell dissemination: a proof-of-principle study for laparoscopic hysterectomy. Acta Obstetricia et Gynecologica Scandinavica. 2019;98(11):1398-1403. doi:10.1111/aogs.13681

36. Anchora LP, Bizzarri N, Kucukmetin A, et al. Investigating the possible impact of peritoneal tumor exposure amongst women with early stage cervical cancer treated with minimally invasive approach. Eur J Surg Oncol. 2020;S0748-S7983(20):30829.

37. Kanao H, Matsuo K, Aoki Y, et al. Feasibility and outcome of total laparoscopic radical hysterectomy with no-look no-touch technique for FIGO IB1 cervical cancer. J Gynecol Oncol. 2019;30(3):e71. doi:10.3802/jgo.2019.30.e71

38. Kimmig R, Ind T. Minimally invasive surgery for cervical cancer: consequences for treatment after LACC Study. J Gynecol Oncol. 2018;29(4):e75. doi:10.3802/jgo.2018.29.e75

\section{Publish your work in this journal}

Cancer Management and Research is an international, peer-reviewed open access journal focusing on cancer research and the optimal use of preventative and integrated treatment interventions to achieve improved outcomes, enhanced survival and quality of life for the cancer patient.
The manuscript management system is completely online and includes a very quick and fair peer-review system, which is all easy to use. Visit http://www.dovepress.com/testimonials.php to read real quotes from published authors. 